\title{
Big Data for National Security in the Era of COVID-19
}

\author{
Pedro Cárdenas ${ }^{1}$, Boguslaw Obara ${ }^{1}$, Ioannis Ivrissimtzis ${ }^{1}$, Ibad Kureshi $^{2}$, and \\ Georgios Theodoropoulos ${ }^{3}$ \\ 1 Dept. Computer Science, Durham University, United Kingdom \\ \{pedro.cardenas-canto, boguslaw .obara, ioannis.ivrissimtzis\}@durham.ac.uk \\ ${ }^{2}$ Inlecom Systems, ibad.kureshi@inlecomsystems.com \\ 3 Dept. of Computer Science and Engineering, Southern University of Science and \\ Technology, China, theogeorgios@gmail.com
}

\begin{abstract}
The COVID-19 epidemic has changed the world dramatically as societies adjust their behaviour to meet the challenges and uncertainties of the new normal. These uncertainties have led to instabilities in several facets of society, most notably health, economy and public order. Increasing discontent within societies in response to government mandated measures to contain the pandemic have triggered social unrest, imposing serious threats to national security. Big Data Analytics can provide a powerful force multiplier to support policy and decision makers to contain the virus while at the same time dealing with such threats to national security. This paper presents the utilisation of a big data forecasting and analytics framework to deal with COVID-19 triggered social unrest. The framework is applied and demonstrated in two different disruptive incidents in the United States of America.
\end{abstract}

Keywords: · COVID-19. Epidemics · Big Data - National Security . Data Analytics · Machine Learning.

\section{Introduction}

Global challenges and emergencies such as climate change, epidemics and natural and man-made calamities present unprecedented governance issues. The COVID-19 pandemic has demonstrated how a global challenge can disrupt more than than 180 countries. Governments across the globe have taken strict decisions aimed at containing the disease and avoiding massive infections, such as curfew, lock-downs, "stay at home" measures, or clustering domestic territories according to its infection rates [1].

Such measures represent a meaningful way to control the disease; however, they also have a negative effect people's lives imposing dramatic changes in the way of life people have been used to. As a result, containment measures have been accompanied by varying degrees of social discontent and unrest, from protests and non-compliance actions to more violent manifestations such as demonstrations and riots [2]. A state's stability may be compromised by such social instability scenarios which can have a negative effect on national security components such as health, economy, and public order [3]. 
Policy and decision-makers need to have at their disposal technological tools, acting as force multipliers and enabling insights about disasters and unfolding situations, so that an assessment of the scale of the threat to national and international security can be made[4,5]. Big Data technologies can provide a powerful means in this endeavour $[6,7]$. As a result the last decade has witnessed the development of several computational platforms that utilise Big Data analytics to derive insights about disruptive situations that can trigger social unrest [8-13].

Contributing to this effort, in earlier work we have presented a framework and associated workflow for the analysis of social media data (Twitter) to derive insights about disruptive events and potential unrest [14-18]. In this paper, this framework is utilised to analyse the COVID-19 pandemic. Our analysis focuses on two areas where acts of social unrest were witnessed as a result of COVID-19 containment measures, namely Michigan and Texas.

The aims and contributions of this paper are twofold. Firstly, to demonstrate the robustness and applicability of our framework for forecasting and analysing important real-world events such as COVID-19 related unrest: would the framework have been able to provide the competent authorities enough notice and insights to deal with the then forthcoming crisis? Secondly, to provide interested stakeholders postmortem insights about COVID-19 social crises with the view to contribute to the global effort to tackle this disruptive situation.

The rest of the paper is organised as follows; Section 2 briefly discusses the impact of pandemics such as COVID-19 on National Security; Section 3 provides an overview of the framework; Section 4 illustrates the operationalisation of the methodology, examining two events regarding COVID-19 related outbreaks; Section 5 concludes the paper.

\section{COVID-19 and National Security}

National security threats refer to those activities that endanger individuals' physical well-being or compromise the stability of the state. Seven components typically describe how national security can be affected based on people as the centre of analysis, also referred to as human security: economic security, food security, health security, environmental security, personal security, communal security and political security [3]. Instabilities are generated due to the disruption of one or more these components leading to protests, riots and other forms of violence [17, 19]. According to the Global Peace Index [20], civil unrest has doubled over the past decade, and riots, strikes and anti-government protests increased by $244 \%$.

Countries around the world define their domestic security threats based on their internal policies. Pandemics are typically considered national security threats due to their negative social, economic and political impacts [22]. As a global pandemic, COVID-19 represents a serious National Security threat [23]. The negative social and economic effects of the lock-downs have provided a pretext for intensifying preexisting social discontent and unrest (e.g. the Black Lives Matter movement or the demonstrations in Hong Kong) as well as new antilockdown demonstrations. These demonstrations in turn act as super-spreader events further exacerbating the negative impacts of the pandemic [21]. 


\section{An Overview of the Framework}

The methodology described in our previous works [14-18], attempts to enrich the security decision-making process scenario. It analyses national security considering its broad spectrum components including but not limited to health and public order; enabling in such a way to detect timely tipping points and examine a variety of situations as riots, protests or events linked to health issues as COVID-19.

The framework consists of two main stages (see Figure 1). An initial phase (Warning Period) continuously analyses data and issues an alert when it identifies that specific societal behavioural characteristics exceed a given threshold (tipping point). The system then gets into its next phase (Crisis Interpretation) by collecting information from numerous sources such as social networking services or websites to attempt to zoom in and provide more in-depth insights that unveil data to construe the unfolding crisis and therefore support authorities and other stakeholders to make better decisions.

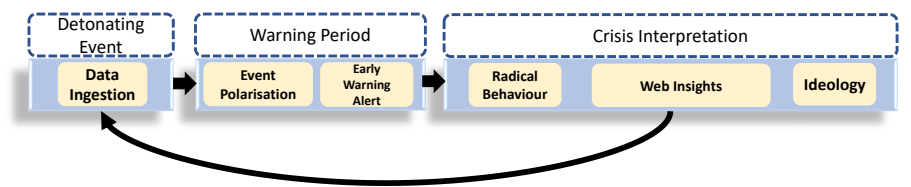

Fig. 1: Conceptual Framework, as described in [14-18].

Under the new normal where COVID-19 tends to modify some behavioural aspects of people's lives, understanding crucial features that directly impact the security of a state come to play. Therefore, the extracted features from the conceptual framework previously mentioned outlines a way to interpret such a health crisis. Table 1 summarises the characteristics used in this work to examine the aforementioned disease outbreak. In the next subsections, we provide an overview of the different stages of the framework.

\begin{tabular}{|l|c|c|c|c|}
\hline \multicolumn{2}{|c|}{ Insights } & \multicolumn{2}{c|}{ Stages } & Web Insights \\
\cline { 2 - 5 } & $\begin{array}{c}\text { Early Warning } \\
\text { Alert }\end{array}$ & Radical Behaviour & Ideology & - \\
\hline $\begin{array}{l}\text { Q1. When do people head towards a situation that evokes that both social } \\
\text { stability and national security components can be compromised? }\end{array}$ & $\checkmark$ & - & - & \\
\hline Q2. Which entities are described by people during the crisis? & - & $\checkmark$ & - & \\
\hline Q3. What are the radical behavioural traits being conveyed? & - & $\checkmark$ & - & \\
\hline Q4. What items are being asked for by individuals in social media? & - & $\checkmark$ & - & \\
\hline Q5. Are hostility and authoritarianism traits present during the incident? & - & - & $\checkmark$ & \\
\hline Q6. Do embedded web resources in social media texts disclose that the national \\
security components have a horizontal escalation over time?
\end{tabular}

Table 1: Insights derived from the Analytics Framework described in [14-18].

\subsection{Event Polarisation and Early Warning Alert (Q1)}

As explained in $[17,24,25]$, a detonating event is an incident that may trigger a disruptive situation that can lead to social unrest and threaten national security 
components. The Warning stage aims to identify which human security components are being affected and if such impact exceeds a certain threshold, to issue an alert.

More particularly the alert is issued when three components, namely, Global Polarisation (GP), Social Media Connectedness (SMC) and Human Security Impact (HSI) have reached a predefined verge, as described in [14]. As a result, the GP process performs a sentiment analysis procedure and when negative polarisation fluctuates above a predefined threshold, triggers the subsequent step. Then, SMC based on a Deep Learning model reveals when individuals are engaged towards the incident. Finally, HSI classifies the data corpus into ten human security aspects (health, public order, transport, economy, people, defence, environment, government, information and life), using unsupervised and supervised learning processes. Afterwards, it determines if human security components have been compromised based on a preconfigured scale.

Once these three steps have been completed, an alert is issued to indicate that the society is heading towards a tipping point, namely a situation where the crisis tends to affect the components that keep a state's stability, which means a point of no return.

\subsection{Radical Behaviour (Q2, Q3 and Q4)}

Social media is a complex and disarranged milieu in both normal conditions and during crises [26]. Nevertheless, emergencies/incidents are complex scenarios where online activity tends to ramp up significantly [27]. Such bursts of activity can provide information linked to numerous topics, but those aspects that may unbalance the integrity of a state gain special attention.

As a result, disruptive expressions may reveal critical aspects, which is why the radical behaviour methodology detailed in our previous work [16], can help to disclose radical nuances based on eight aspects: (1) Creation of instability scenarios, (2) Identification of affected entities (people, locations or facilities), (3) Identification of likely affected entities due to the proximity to the incident, (4) Dissection of the intentions expressed towards an entity, (5) Dissemination degree of the crisis (widespread or local incident), (6) Detection of violent expressions, (7) Classification of violent expressions, and (8) Necessities shared by individuals amid the crisis.

The radical behaviour architecture comprises five stages, namely, Instability Scenarios, Entity Extraction, Wordlists Creation, Content Analytics and Data Interpretation, as detailed in [16]. The collection of procedures previously mentioned is underpinned by an array of interconnected computational techniques such as deep learning, natural language processing, supervised and unsupervised learning. It should be noted that the extraction of the insights above depends on the nature of the incident since a violent public disorder or a protest amidst a pandemic have dissimilar roots, and therefore features such as violent expressions cannot be detected with the same frequency.

The coronavirus (COVID-19) has changed the way people used to live, work or even communicate. As part of the communication cycle, individuals use words or specific terms to embody the situation they have to cope with. The pandemic 
has drawn to the scene numerous terms that enrich the vocabulary necessary to convey a message. Therefore, the wordlist creation step previously mentioned was enriched by adding a comprehensive glossary that included terms such as case fatality rate (CFR) or personal protective equipment (PPE) [28-30].

\section{$3.3 \quad$ Ideology (Q5)}

Ideology refers to ideas and beliefs taken from a more complex system of ideas such as popular sovereignty or nationalism [31]. One more way to understand this concept is by linking it to the processes of giving legitimacy to the power of a dominant group [32]. In both scenarios, the term ideology describes fundamental beliefs shared by a social group [33].

However, during an organised public demonstration or a riot, ideas, beliefs and actions directed against authorities or other groups [34] may emerge. Consequently, collective emotions play a big role as they denote appraisals of superiority/inferiority, goal obstruction/injustices or intolerability, also described as hostility by [35]. Protests and other disruptive incidents are two examples of events where hostility may be present and where tints of violence can be a signal of the instability of the state, which in turn may represent the prelude of a crisis $[35,36]$.

In addition, such disruptive events may evolve due to the fact that people do not empathise with decisions or activities performed by those who hold the "proper authority", which can be manifested in aggression, submission and conventionalism against them, also known as authoritarianism [37, 38]. Governments around the globe have introduced different measures to contain the virus. Notwithstanding, the nature of the restrictions may generate traits of hostility and authoritarianism, which is why both ideological characteristics will be used in this work, similarly to the methodology proposed in our work [18].

The ideology traits are spotted following a data analytics procedure that involves the processing of emotions in unstructured data (tweets) to identify the internal components of authoritarianism and hostility, followed by a deep generative model (variational autoencoders) centred on separating the ideological features from the rest of the data. Lastly, such information is compared to a precalibrated model to determine the presence of such ideological characteristics.

\subsection{Web Insights (Q6)}

While a disruptive event occurs, individuals adopt responses shaped by the nature of the incident, which runs from protests and large-scale mobilisations to violent activity. As a result of such activities, human security components get affected, since a violent incident do not only impacts a prima facie component "public order", but "health" as more protesters can be hurt as the situation gets nuanced by more aggressive reactions.

Such an aspect gains importance since national security can be compromised when the number of human security components increases over time, which is called horizontal escalation, as described in [39]. In line with this idea, web resources (websites, social networking services, independent websites or information outlets) can be used as a valuable tool to disseminate information within 
the Internet and work as a mouthpiece to organise demonstrations. In a preceding work [15] an architecture aimed at analysing the horizontal escalation of human security components along on-line participative channels was presented. A classification model underpins this work to cluster the numerous human security components from the data corpus, and it yields baseline thresholds to analyse the aforementioned escalation characteristics in future events.

\section{Analysing Two COVID-19 disruptive events}

As stated earlier, the goal of the conceptual framework is to monitor the state of the society at any particular moment and in case of an alert, to derive deeper insights about the situation and the threat it may constitute to national security. With this goal in mind, two incidents of social unrest incidents related to COVID19 outbreak that occurred in April 2020 were considered, namely, Michigan and Texas.

The dyad of events was selected in view of people's reactions notwithstanding the strict local restrictions imposed to tackle the pandemic. In both cases, citizens protested after local governments adopted lockdown rules.

In the case of Texas, rallies were organised to show disagreement against local restriction measures, where people demanded to reopen economies [40, 41].

By contrast, in Michigan, a convoy of thousands of motorists drove from all over the state to protest the governor's stay-at-home order's extension. The protest, known now as Operation Gridlock, involved clogging the streets surrounding the Michigan State Capitol, including the Capitol Loop, with their vehicles, drawing national attention [42].

\subsection{Data Collection and Cleansing}

A data corpus of six million tweets written in English was collected from 10th to 20th April 2020, by considering hashtags such as \#covid, \#coronavirus, \#coronavirusoutbreak and \#coronaviruspandemic. Then, two data subsets were extracted from the anterior dataset, and where each subset has a unique combination of tweets based on specific parameters such as hashtags that were linked to the studied entities (locations), as depicted in Table 2.

Once these two subsets have been created, tweets appertained to the former clusters were cleansed following the steps described below: (1) URLs were extracted; (2) RT and mention terms were removed; (3) contractions were replaced, for instance, wasn't: was not; (4) punctuation marks were removed; (5) emoticons were replaced by words; (6) Internet slang was replaced by complete expressions using a preconfigured dictionary, such as AFAIK: "as far as I know", ASAP: "as soon as possible" or BBL: "be back later".

\subsection{Early Warning Alert (Q1)}

Once an incident has unfolded, the stability of the state tends to be compromised due to national security components instability, whereby identifying if an event heads toward a significant disruption scenario becomes a primary task. In light 


\begin{tabular}{|c|c|c|c|}
\hline \multicolumn{2}{|c|}{ Dataset 1 (Michigan ,USA) } & \multicolumn{2}{c|}{ Dataset 2 (Texas, USA) } \\
\hline \#michigan & \#michiganprotest & \#texas & \#reopentexas \\
\hline \#liberatemichigan & \#michiganlockdown & \#opentexas & \#stayhometexas \\
\hline \#freemichigan & \#michiganshutdown & \#texasstrong & \#texans \\
\hline
\end{tabular}

Table 2: Popular Hashtags posted on April 2020 linked to two locations, namely, Michigan and Texas. The depicted hashtags in the table involve two tokens, the first one associated with a location and the other with a noun/verb, the difference between both is highlighted by two colours -red and black.

of this idea, the analysis of three indicators namely, Global Polarisation, Social Media Connectedness and Human Security Impact enable the identification of the real nature of the event by triggering an early warning alert, as described in Section 3 [14].

Michigan Figure 2.I shows that the system would generate an alert on 14th April 2020, a day before protests began because of the governor's order "stay at home" was declared, and six days before protests boosted (19th April 2020), and where the spotted alarm suggests that the internal cohesion amongst national security components has been disrupted.
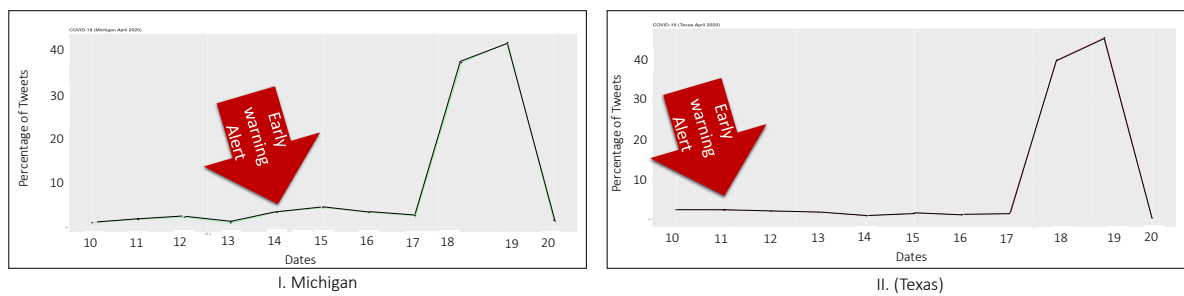

Fig. 2: Early Warning Alert Detection in the events of Michigan and Texas in April 2020.

Texas As depicted in Figure 2.II on 11th April 2020, an alert was triggered by the early warning process, eight days before protests against Coronavirus increased (19th April 2020).

\subsection{Radical Behaviour (Q2, Q3 and Q4)}

The analysis of radical behavioural traits can bring critical information to the scene. Table 1 shows that addressing Q2, Q3 and Q4, enables the identification of entities, behavioural traits and required objects amid the pandemic; which is why the radical behaviour analysis methodology proposed in our previous work [16] was used to enrich this part of the analysis. 


\begin{tabular}{|c|c|c|c|c|c|c|c|c|}
\hline \multirow[b]{2}{*}{ Location } & \multicolumn{8}{|c|}{ Dates (2020) } \\
\hline & April 10 & April 11 & April 12 & April 15 & April 16 & April 17 & April 18 & April 19 \\
\hline \multirow{8}{*}{ I. Michigan } & & & & $\begin{array}{l}\text { Violating -> } \\
\text { Lockdown }\end{array}$ & & Stop -> Insanity & $\begin{array}{l}\text { Cancel -> } \\
\text { Lockdown }\end{array}$ & Avoid -> Quarantine \\
\hline & & & & Disagree -> Curfew & & Take $>>$ Streets & $\begin{array}{l}\text { Protest -> } \\
\text { Lockdown }\end{array}$ & Violating $->$ Distancing \\
\hline & & & & Protest $->$ Rally & & $\begin{array}{l}\text { Break -> } \\
\text { Demand }\end{array}$ & Take $->$ Lockdown & Michigan $>$ Edict \\
\hline & & & & Protest $->$ Virus & & $\begin{array}{l}\text { Protest -> } \\
\text { Michigan }\end{array}$ & $\begin{array}{l}\text { Protest -> } \\
\text { Distancing }\end{array}$ & Need $>>$ Lawmaker \\
\hline & & & & & & Wear $\rightarrow$ Masks & $\begin{array}{l}\text { Demand -> } \\
\text { Reopening }\end{array}$ & Break > Curfew \\
\hline & & & & & & Shut $>>$ Now & $\begin{array}{l}\text { Liberate -> } \\
\text { Lockdown }\end{array}$ & Want $>$ Cure \\
\hline & & & & & & & Block $->$ Roads & Want $->P P E$ \\
\hline & & & & & & & Rally-> Arizona & Take $>>$ Streets \\
\hline \multirow{10}{*}{ II. Texas } & & $\begin{array}{l}\text { Allow -> } \\
\text { Business }\end{array}$ & Halt -> Covid & & & $\begin{array}{l}\text { Reopen -> } \\
\text { Government }\end{array}$ & $\begin{array}{l}\text { Spreading -> } \\
\text { Frustation }\end{array}$ & Hoarding $>P P E$ \\
\hline & & Avoid $->$ Corona & $\begin{array}{c}\text { Develop -> } \\
\text { Diarrhea }\end{array}$ & & & $\begin{array}{c}\text { Need -> } \\
\text { Michigan }\end{array}$ & See $->$ Outrage & Open $>>$ Quarantine \\
\hline & & $\begin{array}{c}\text { Lifting -> } \\
\text { Quarantine }\end{array}$ & $\begin{array}{c}\text { Open -> } \\
\text { Employment }\end{array}$ & & & Close $->$ Schools & Wear $\rightarrow$ PPE & Observe $->$ Distancing \\
\hline & & Reopen $>$ Texas & Help $>$ Employees & & & & Wear $>$ Facemask & $\begin{array}{l}\text { Protesting -> } \\
\text { Coronavirus }\end{array}$ \\
\hline & & Care $>>$ Lives & Puts $>$ Halt & & & & $\begin{array}{c}\text { Authorizing -> } \\
\text { Reopen }\end{array}$ & Violate $>>$ Lockdown \\
\hline & & Rise $>>$ Deaths & & & & & & Protest $>$ L Lockdown \\
\hline & & Want $\rightarrow$ Nurses & & & & & & Support -> Boycott \\
\hline & & & & & & & & Make -> Masks \\
\hline & & & & & & & & Rally -> Whattsapp \\
\hline & & & & & & & & Rally -> Austin Texas \\
\hline
\end{tabular}

Table 3: Disruptive Expressions extracted using Word Embeddings and Direct Object (Texas and Michigan).

Michigan Q2. and Q3. In order to facilitate the narrative, in this case, Q2 and Q3 will be presented together. It can be seen in Table 3.I that on April 15th 2020 protesters were conveying messages regarding violating the lockdown as well as showing disagreement towards such a measure. In contrast, two days later messages that expressed an intention to take streets were disseminated, coupled with messages that urged people to wear masks while protesting; moreover, messages that suggested a location to protest were conveyed as well, namely Michigan.

On 18th and 19th April 2020, intentions related to cancelling lockdown and continue protesting due to the imposed measures were spread. In addition, some other ideas were present such as a demanding to reopen, avoiding the quarantine and liberating the lockdown.

Actions tended to affect different means of communication were also conveyed, as blocking roads or taking the streets.

Q4. Lastly, messages where individuals convey their personal needs as PPE (personal protective equipment) or a cure for the COVID-19 were shared likewise, see Table 3.I.

Texas Q2. Radical behavioural traits revealed that individuals expressed some ideas linked to reopening a specific location, Texas, after the lockdown, as shown in Table 3.II. In addition, according to the Levin's classification[43], the verb "need" expresses that a person desires something. Following this argument, on April 17th 2020, messages that conveyed a desire that a different location, Michigan, joined the incident were posted, which suggests that the state is dealing with a widespread event, since different cities are mentioned, as explained in [44]. 
Q3. Social media users (Twitter) exposed concepts connected to the fact of allowing business in the city, lifting the quarantine and contempt towards Coronavirus, as described in Table 3.II. However, in the following dates (17th, 18th and 19th April 2020) messages that instigate to violate the lockdown, protest, underpin the boycott, close schools, wear PPE and spread frustration were shared.

Q4. Concerns about health were also transmitted, such as the need of nurses and the rise of deaths.

\subsection{Ideology (Q5)}

Ideological traits just as authoritarianism and hostility can reveal two main aspects. Firstly, authoritarianism denotes that individuals do not empathise with decisions or activities performed by those who hold the "proper authority" [37, 38]. Secondly, hostility enables the identification of collective emotions which are seen whilst disruptive events take place $[35,36]$.

In order to begin the dissection of ideology in the COVID-19 datasets, a sentiment analysis process was performed, then tweets with negative polarisation were selected accordingly. In all two cases, negative sentiments played the predominant role, where Michigan had the highest figures with 51\%, while Texas had $35 \%$. Then authoritarianism and hostility traits were computed using the methodology and thresholds proposed in our previous study [18]. Consistent with such steps, when the calculated variables of authoritarianism (aggressiveness, submission and conventionalism) and hostility (anger, contempt and disgust) were above the predefined thresholds, such results suggested that the aforementioned ideological traits were present.
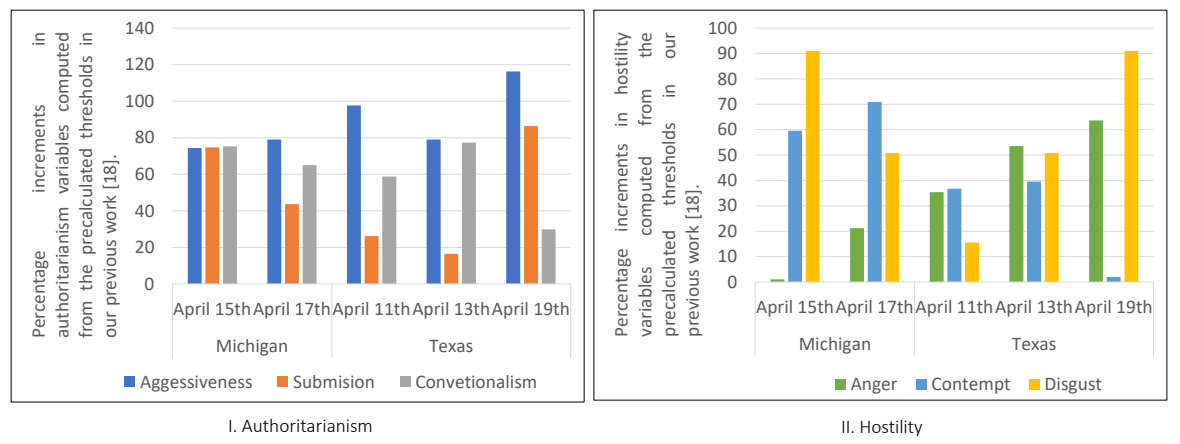

Fig. 3: Ideological traits (Michigan and Texas).

Michigan A day after the early warning alert was triggered (April 14th 2020), signs of authoritarianism and hostility were detected (April 15th 2020), just the same date where the local government imposed the lockdown in the city, see Figure 3 .

Texas On April 11th 2020, ideological traits were detected, just the same date as the early warning alert was triggered, see Figure 3. As a result, this specific 
point turns into a medullary axis, since it discloses that people were concerned about aspects such as the COVID-19 death toll or lifting the quarantine, see radical behaviour analysis subsection 4.3 and Table 3.II.

Regarding authoritarianism, it should be noted that in all the two studied cases, aggressiveness was above $60 \%$ of the precalculated threshold, while the other two variables had irregular increments. This consistent increase in aggressiveness suggests that people were conveying messages that denote prejudice/intolerance against a topic [38] such as a lockdown, curfew or quarantine, see Table 3 .

\subsection{Web Insights (Q6)}

During an incident or a health crisis such as COVID-19, individuals and organisations tend to use such digital channels to contribute disseminating data such as breaking news, messages or pictures, which can help to understand whether a crisis has escalated over time. Hence, as described in Section III, the web insights methodology described in our previous work [15] enables the analysis of the horizontal escalation of national security components. In accordance with the proposed methodology, URLs were classified according to a comprehensive list of entities created over the Wikidata knowledge base. As a result, a web scrapping process was conducted to retrieve the content of such web resources.

Michigan It can be seen in Figures 4.I and 4.II, that only two media resources were embedded in people's messages while posting a tweet, namely Independent Websites and Social Networking Services.

On April 14th 2020, when the early warning alert was triggered, Social Networking Services (Instagram and Twitter) were used to convey that one national security component was being affected, in this case, health. One day later, messages posted on those social media sites showed that four national security components were unbalanced (information, defence, business and health). Such increment in the number of affected components (from one to four), discloses a horizontal escalation, that according to [39] may represent a disruptive situation, see Figure 4.I.

It should be noted that both business and government components, had the highest intensities, which may complement the behavioural traits previously extracted that referred to violating the lockdown and the disagreement towards that measure (see Table 3.I).

On the other hand, Independent Websites showed on April 15th 2020, that three national security components were struck, namely defence, information and government, where the latest had the highest intensity figure. Such a result suggests that those web resources were providing a more detailed description of the government's activity (see Figure 4.II).

On the following days (17th, 18th and 19th April 2020), both Independent Websites and Social Networking Services published content related to health and information, such a result becomes relevant since, on April 19th, COVID-19 cases began to spike [42]. By contrast, only Social Networking Services revealed information about two more components (people and public order), as displayed in Figure 4.I. 


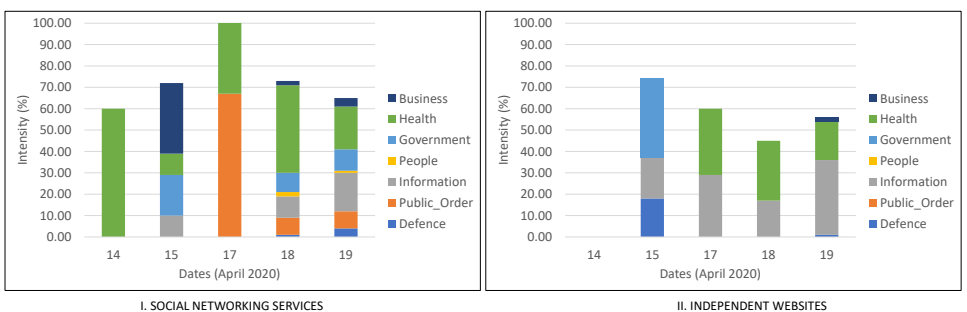

Fig. 4: Horizontal Escalation of the National Security Comoponents during the protests in Michigan (April 2020)

Texas Figure 5.I, 5.II and 5.III show that three digital web resources were used by people to disseminate information amidst the protests, namely, Social Networking Services, Independent Websites and Non-Profit Organisations.

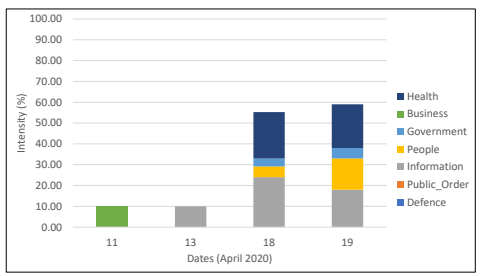

SOCIAL NETWORKING SERVICES

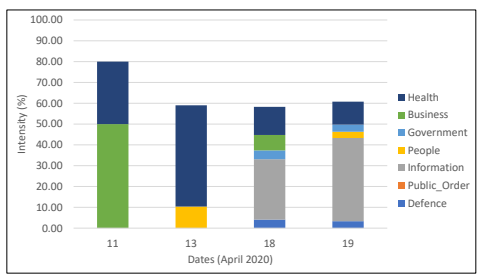

INDEPENDENT WEBSITES

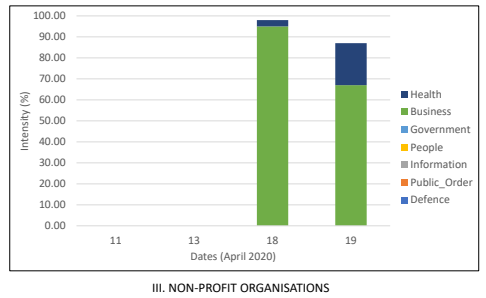

Fig. 5: Horizontal Escalation of the National Security Comoponents during the protests in Texas (April 2020).

As mentioned earlier, the early warning alert and ideological traits were spotted on the same date (11th April 2020). Unlike the prior case, the Independent Websites were used more intensively since they unveiled that two national security components were disrupted, business and health; while Social Networking Services showed that only one component was affected -business with $80 \%$ less intensity than Independent Websites (IW).

Visible changes are displayed between 13th and 18th April 2020, as IW and Social Networking Services (SNS) showed an increased number of affected components, which exposed a horizontal escalation across the national security vulnerable factors, which went from two to five for IW, and from one to four for SNS. 
In addition, Non-profit organisations played a crucial role on 18th and 19th April 2020, because inherent topics in business and health were shared by them. Nevertheless, intensity health levels had a considerable increase of $85 \%$; by contrast, health levels in SNS and IW remained with little changes, nearly $7 \%$ on average. Such a difference indicates that Non-profit organisations were stressing issues linked to health.

Finally, it should be noted that on April 19th where the highest burst of online activity took place (see Figure 2.II), SNS were used to convey more messages linked to people, which is supported by an increase of $70 \%$; whereas IW were focused on disseminating data regarding information, where such component had an increment close to $28 \%$.

\section{Conclusions}

As COVID-19 has so vividly demonstrated, pandemics constitute a serious National Security threat. Big Data Analytics technologies can provide a powerful force multiplier in the endeavour of competent authorities and stakeholders to manage the pandemic while minimising the security threats it imposes.

This paper has discussed the utilisation of a holistic Data Analytics framework for analysing national security aspects in the context of COVID-19. Two real-world cases were considered where authorities' measures to contain the disease via lockdowns resulted in protests and social unrest, namely Michigan and Texas. In both cases the system proved its ability to provide early warning well in advance of the demonstrations (six and eight days respectively). It also demonstrated its capacity to provide insights enabling the better understanding and interpretation of the crisis. As a crisis is unfolding uncertainty is a crucial element and the lack of information is a variable that can obstruct the decision-making process.

Future work will fully integrate and automate the framework, utilising additional analytics approaches and making the various thresholds involved adaptive to the socio-economic context of deployment.

\section{References}

1. Kharroubi S, Saleh F. Are Lockdown Measures Effective Against COVID-19?. Front Public Health. 2020;8:549692. Published 2020 Oct 22. doi:10.3389/fpubh.2020.549692.

2. Peretti-Watel, P., Seror, V., Cortaredona, S., Launay, O., Raude, J., Verger, P., et al. Attitudes about COVID-19 Lockdown among General Population, France, March 2020. Emerg Infect Dis. 2021;27(1):301-303. https://dx.doi.org/10.3201/eid2701.201377. (2021).

3. Human Development Report, United Nations Development Program: New York and Oxford: Oxford University Press, 22-33 (1994).

4. Kureshi,I., Theodoropoulos, G., Magina,E., O'Hare, G., Roche,J., Towards An InfoSymbiotic Framework For Disaster Risk Management, the 19th IEEE/ACM International Symposium on Distributed Simulation and Real Time Applications (DS-RT 2015), Xinhua International Hotel, Chengdu, China, October 14 - 16. (2015).

5. Toth T., Theodoropoulos G., Boland S., Kureshi I., Ghandar A.: Global Challenge Governance: Time for Big Modelling?, 2019 IEEE 18th International Conference on 
Cognitive Informatics \& Cognitive Computing (ICCI*CC), Milan, Italy, pp. 244253. (2019).

6. Roff, H., Uncomfortable Ground Truths: Predictive Analytics and National Security. Brookings National Security Report. (2020).

7. Akhgar, B., Saathoff, G., Arabnia, H., Hill, R., Staniforth, A., Bayerl, P., Application of Big Data for National Security: A Practitioner's Guide to Emerging Technologies. Butterworth-Heinemann, Paperback ISBN: 9780128019672, eBook ISBN: 9780128019733. (2015).

8. Dolyle, A., et al. The EMBERS architecture for streaming predictive analytics, IEEE International Conference on Big Data, USA. (2014).

9. ICEWS Homepage, https://Imt.co/3owTj8L. Last accessed 10 Jan. 2021.

10. Muthiah S., Butler P., Khandpur R. P., Saraf P., Self N., Rozovskaya A., Zhao L., Cadena J., Lu C.-T., Vullikanti A., Marathe A. , Summers K., Katz G., Doyle A., Arredondo J., Gupta D. K., Mares D., and Ramakrishnan N.: EMBERS at 4 years: Experiences operating an open source indicators forecasting system, Proceedings of the 22nd ACM SIGKDD. New York, NY, USA. (2016).

11. Parang S. and Naren R.: EMBERS AutoGSR: Automated Coding of Civil Unrest Events. Proceedings of the 22nd ACM SIGKDD International Conference on Knowledge Discovery and Data Mining (KDD '16). Association for Computing Machinery, New York, NY, USA. (2016).

12. Zhang X., Li J., Zhang X., Fu J., and Wang D.: Construction of a Geopolitical Environment Simulation and Prediction Platform Coupling Multi-Source Geopolitical Environmental Factors, Science and Technology Review 36, no, 3. (2018).

13. Van Puyvelde, D. , Coulthart, S. and Hossain, M. S.: Beyond the buzzword: big data and national security decision-making. International Affairs, 93(6). (2017).

14. Cárdenas P., Theodoropoulos G., Obara B. and Kureshi I.: Defining an alert mechanism for detecting likely threats to National Security. IEEE International Conference on Big Data. USA. (2018).

15. Cárdenas P., Theodoropoulos G. and Obara B.: Web Insights for National Security: Analysing Participative Online Activity to Interpret Crises, IEEE International Conference on Cognitive Informatics and Cognitive Computing, Italy. (2019).

16. Cárdenas P., Obara B., Theodoropoulos G. and Kureshi I.: Analysing Social Media as a Hybrid Tool to Detect and Interpret likely Radical Behavioural Traits for National Security, IEEE International Conference on Big Data. USA. (2019).

17. Cárdenas P., Theodoropoulos G., Obara B. and Kureshi I.: A Conceptual Framework for Social Movements Analytics for National Security. The International Conference on Computational Science. (2018).

18. Cárdenas P., Theodoropoulos G., Obara B. and Kureshi I.: Unveiling Ideological Features Through Data Analytics to Construe National Security Instabilities, IEEE International Conference on Big Data. USA. (2020).

19. Idris M.Y.: Social Instability, Policy Uncertainty, and Financial Risk: Evidence from the Egyptian Exchange and Borse de Tunis, Belfer Center for Science and International Affairs Harvard Kennedy School. (2015).

20. Institute for Economics and Peace: Global Peace Index 2020. (2020).

21. Wilson, J., US lockdown protests may have spread virus widely, cellphone data suggests, The Guardian, 18 May. (2020).

22. Davies S.E.: National security and pandemics, United Nations, UN Chronicle. (2013).

23. Klarevas, L., Clarke, C., COVID-19 Is a Threat to National Security. Let's Start Treating It as Such, Just Security. (2020). 
24. Sandoval-Almazan R. and Gil-Garcia J. R.: Cyberactivism through Social Media: Twitter, YouTube, and the Mexican Political Movement "I'm Number 132". Hawaii International Conference on System Sciences. (2013).

25. Storck M.: The role of social media in political mobilisation: A case study of the January 2011 Egyptian uprising. University of St Andrews, Scotland. (2011).

26. Castillo C.: Big Crisis Data: Social Media in Disasters and Time-Critical Situations. Cambridge University Press. (2016).

27. Bagrow JP., Wang D., Barabási A-L.:Collective Response of Human Populations to Large-Scale Emergencies. PLoS ONE 6(3). (2011).

28. Personal Protective Equipment: Questions and Answers, Centers for Disease Control and Prevention Homepage., https://bit.1y/38wHUQU. Last accessed 10 May. 2020.

29. Coronavirus (COVID-19) Outbreak Glossary, Kaiser Family Foundation. https: //bit.1y/3bn4j4R. Last accessed 15 January 2021.

30. Becker, A., COVID-19 crisis catalog: A glossary of terms, Texas Medical Center Home Page. 26 May. (2020).

31. Rudé, G.: Ideology and Popular Protest. Historical Reflections / Réflexions Historiques, 3(2), 69-77. (1976).

32. Thompson, J. B.: Studies in the Theory of Ideology. Cambridge: Polity Press. (1984).

33. Teun A. Van Dijk.:Ideology and discourse analysis, Journal of Political Ideologies, 11:2. (2006).

34. Gutting, R.S. Contentious Activities, Disrespectful Protesters: Effect of Protest Context on Protest Support and Mobilization Across Ideology and Authoritarianism. Polit Behav. (2019).

35. Matsumoto D. et al., The Role of Intergroup Emotions in Political Violence, Current Directions in Psychological Science, 24(5). (2015).

36. Troost D., Emotions of Protest, Emotions in Politics. Palgrave Studies in Political Psychology series. Palgrave Macmillan, London. (2013).

37. Saunders B.A., Ngo J.: The Right-Wing Authoritarianism Scale. In: Zeigler-Hill V., Shackelford T. (eds) Encyclopedia of Personality and Individual Differences. Springer, Cham.(2017).

38. Dunwoody, P., Funke, F.. The Aggression-Submission-Conventionalism Scale: Testing a New Three Factor Measure of Authoritarianism. Journal of Social and Political Psychology, North America. (2016).

39. Patrick J. Cullen and Erik Reichborn-Kjennerud: MCDC Countering Hybrid Warfare Project:Understanding Hybrid Warfare. Multinational Capability Development Campaign. (2017).

40. Jeffery, A., Scenes of protests across the country demanding states reopen the economy amid coronavirus pandemic, CNBC. 18 April. (2020).

41. Hundreds protest COVID-19 orders at Texas Capitol, FOX4News Homepage https://bit.ly/38IA1rl. Last accessed 14 Jan. 2021.

42. Hutchinson, B., Operation Gridlock': Convoy in Michigan's capital protests stayat-home orders, ABCNews. April 16. (2020).

43. Levin B. English Verb Classes and Alternations: A Preliminary Investigation. University of Chicago Press, Chicago. (1993).

44. Reed T., Belvin K., Hickman M., Kokolus M., Mendoza F., Phelps A. and Reisler K.: Open Source Indicators Program Handbook. The MITRE Corporation, USA. (2017). 